\title{
The Effect of Mixed Organic Solvents Extract of Trachyspermum ammi with Different Concentrations on the Body Weight of Mice
}

\author{
Ali Akbar Moghadamnia ${ }^{1}$, Maria Hashemi ${ }^{2}$, Parvin Sajadi Kaboudi ${ }^{3}$, \& Zahra Geraili ${ }^{4}$ \\ ${ }^{1}$ Cellular and Molecular Biology Research Center, Health Research Institute, Babol University of Medical \\ Sciences, Babol, I.R. Iran \\ ${ }^{2}$ Department of Pharmacology, School of Medicine, Babol University of Medical Sciences, Babol, I.R Iran \\ ${ }^{3}$ Social Determinants of Health Research Center, Health Research Institute, Babol University of Medical \\ Sciences, Babol, I.R. Iran \\ ${ }^{4}$ Department of Statistic and Epidmiology, School of Medicine, Babol University of Medical Sciences, Babol, \\ I.R Iran \\ Correspondence: Parvin Sajadi Kaboudi, Social Determinants of Health Research Center, Health Research \\ Institute, Babol University of Medical Sciences, Babol, I.R. Iran. Tel: 98-911-114-8704, Email: \\ psajadi@yahoo.com.
}

Received: April 17, 2019

Accepted: May 10, 2019

Online Published: May 29, 2019

doi:10.5539/jmbr.v9n1p49

URL: https://doi.org/10.5539/jmbr.v9n1p49

\begin{abstract}
Background and Aim. In traditional medicine, the use of Trachyspermum ammi, commonly known as 'Ajwain', is recommended to improve digestive function of the stomach and has effects on body weight. The present study aims to determine the effect different concentrations of mixed organic solvents extract (MOSE) of Trachyspermum ammi on mice compared with control group.

Materials and Methods. This experimental-interventional study was performed on mice weighing an average of $21 \mathrm{gr}$, selected through random allocation method. The mice were divided into four groups of 24 (one control group and three case groups), receiving $0.5,1$ and 2\% concentrations or density of MOSE of Trachyspermum ammi $(0.001 \mathrm{mg} / \mathrm{kg})$. First, the dried fruit of Trachyspermum ammi was powdered and then, it was extracted using various organic solvents including petroleum ether, chloroform, ethyl acetate and ethyl alcohol. The extract was fed to the mice for 14 days and their weight was controlled every day.

Results. The hypothesis of diversity in the weight gain of mice among the four groups after 15 days was significant; weight gain in control group was significantly higher than other groups $(p<0.05)$. In addition, comparing the weight gain of the mice that received different concentrations of MOSE of Trachyspermum ammi $(0.5,1$ and $2 \%)$ did not show a significant difference $(\mathrm{p}<0.05)$.
\end{abstract}

Conclusion. The use of Trachyspermum ammi plant can not be effect on body weight compared to the control group. This could not be a suitable way to weight change through diet.

Keywords: Mixed organic solvents extract of Trachyspermum ammi, Mice, Weight gain

\section{Introduction}

Trachyspermum ammi is a medicinal herb which is used to cure central nervous system (CNS) involvement, gastrointestinal disorders such as nausea, vomiting, abdominal cramps and loss of appetite, reduces the pain (Markesbery, 1997; Mohanty, 2017; Sivropoulou et al., 1996). This plant is broadly distributed and cultivated in many areas of Mediterranean countries and Iran, Afghanistan, Pakistan, Egypt, and India as well as European region(Bairwa, Sodha, \& Rajawat, 2012). An annual herbaceous plant belonging to the highly valued medicinally serious family, Apiaceae.

The past of this plant is not completely clear, but we know that in the traditional medicine it was prescribed to improve the digestive process or digestive diseases like as flatulence(Vasudevan, Vembar, Veeraraghavan, \& Haranath, 2000). The most important materials obtained from Trachyspermum ammi are 35-50 percent thymol, 15-20 percent cymene and 30-40 percent $\alpha$-pinene(Ishikawa, Sega, \& Kitajima, 2001). Trachyspermum ammi (Apiaceae) against Setaria digitata worms has been assessed(Chahal, Dhaiwal, Kumar, Kataria, \& Singla, 2017; 
Jeet et al., 2012; Mathew, Misra-Bhattacharya, Perumal, \& Muthuswamy, 2008). The crude extract showed significant activity against the adult Setaria digitata. In 2002 a study about the effect of Trachyspermum ammi extract on smooth muscles named the spasmolytic and antispasmodic effects of complex products of some medicinal herbs on guinea pigs showed that this plant loosens the smooth muscle of ileum wall(Hejazian, Bagheri, \& Safari, 2014; Jeet et al., 2012). The effect of mixed organic solvents extract (MOSE) of Trachyspermum ammi on the weight has not been studied a lot in Iran or other countries. Most of the studies are indirectly related to the matter.

In 2004 some seven day chickens were fed with the extract which its concentration was two or ten percent during nine weeks, and the study showed that 10 percent concentration had toxic effects but was not fatal. This diet decreased weighting and so it caused enterohepatonephropathy, anemia and regulating the quantity of aspartate aminotransferase (AST) enzymes and C-reactive protein (CRP), cholesterol, total lipid and uric acid a two percent concentration extract had milder effects of these types(Saleem, Riaz, Ahmad, \& Saleem, 2017). If we prove that Trachyspermum ammi affects the body weight, this (subject) may determine to explanation of the digestive effects(Platel \& Srinivasan, 2001). The aim of this research is the effect of Trachyspermum ammi extract with different concentrations on the body weight of mice.

\section{Materials and Methods}

It is an experimental interventional study on 4 groups mice (in each group 24) and the samples of each group were chosen in random allocation way. The male small white mice were about $21 \mathrm{gr}$ and were kept in special cages in lab. All of them with their food were brought from Pasteur institute.

\subsection{Extraction}

At first we ground the dried fruit of Trachyspermum ammi in to powder. Then we extracted through organic solvents like petroleum ether, chloroform, ethyl acetat and ethyl alcohol.

We added $50 \mathrm{~mL}$ of petroleum ether and $50 \mathrm{~mL}$ chloroform to $20 \mathrm{gr}$ of Trachyspermum ammi powder for separating the fat and terpenoid. Steeped in special dishes for 48 hours, we mixed the solution with $50 \mathrm{~mL}$ of ethyl alcohol and $50 \mathrm{~mL}$ of ethyl acetat. This solution was steeped for another 48 hours. After passing through the filter paper, it is kept in separate plates in lab temperature. We didn't use of heat because for preventing of changing in the chemical properties. After evaporating about two weeks, the Trachyspermum ammi extract is ready to use (13). How to prepare the solutions: the solutions were prepared daily and the extract was saved of the refrigerator. To prepare 5\%,1\% and $2 \%$ solutions of Trachyspermum ammi, we dissolve 5, 10 and $20 \mathrm{~mL}$ of the extract in $1000 \mathrm{~mL}$ of distilled water. This oily solution must be shaken in to emulation. To do the experiments, four groups of mice with the weight of about 21 gr were chosen and then they were divided into a control and three case groups. The case groups received $0-5 \%, 1 \%$ and $2 \%$ of Trachyspermum ammi extract and the control group received distilled water. The study has been done regularly during fourteen successive days in the certain time. The weight of the mice was recorded before feeding every day and on the fifteenth day the experiment was over.

\subsection{Statistical Analysis}

In all of the studied groups, changes in the body weight of the mice were evaluated and after entering the data, statistical analysis was performed with SPSS Version 16.0 statistic software. Kruskal-Wallis nonparametric test and Mann-Whitney test were also performed. The p- values were considered significant when $<0.05$.

\section{Results}

Our finding presented components of the ethanolic extract of Trachyspermum ammi included $\gamma$-terpinene, p-cymene, and thymol. The results of the mean weight gain of mice in the control group and different concentrations of MOSE of Trachyspermum ammi after 15 days are as follows (Fig. 1).

The hypothesis of diversity in the weight gain of mice after 15 days was evaluated among the four study groups (control group and three groups fed with different concentrations of MOSE of Trachyspermum ammi) using Kruskal-Wallis test (Table 1). Based on the results of this test, there was a significant difference among the four groups $(\mathrm{p}<0.05)$. The mean weight gain of the control group was higher than the other three groups. Paired comparisons between the groups using Mann-Whitney test showed that the weight gain of the control group was significantly different from the three groups fed with different concentrations of MOSE of Trachyspermum ammi 
$(\mathrm{p}<0.05)$. However, the comparison of weight gain of the mice fed with different concentrations of MOSE of Trachyspermum ammi showed no significant difference ( $>0.05)$.

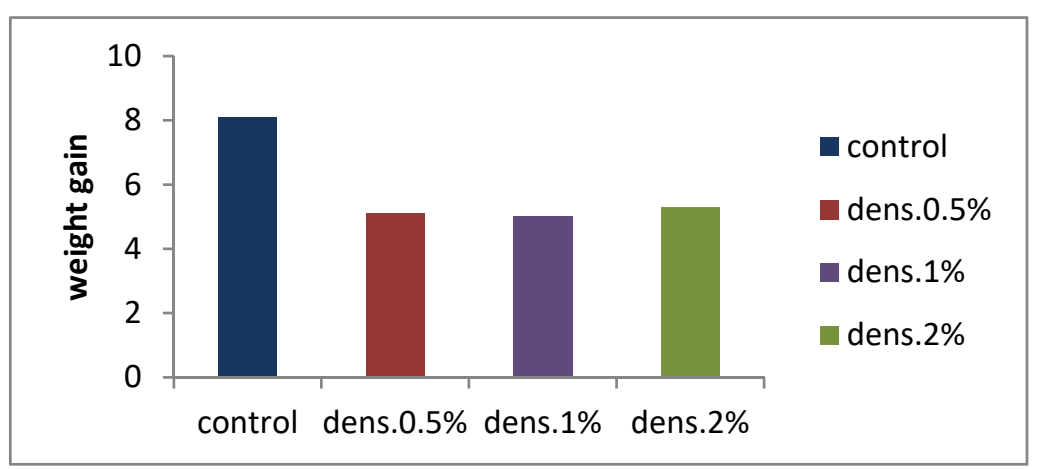

Figure 1. The mean weight gain of mice using different concentrations of MOSE of Trachyspermum ammi and the control group

Table 1. Comparison of the mean rank of weight gain of mice after 15 days in the four study groups

\begin{tabular}{llll}
\hline Groups & Number of mice & Mean rank & P-value \\
\hline Control & 24 & 78.5 & 0.036 \\
$0.5 \%$ & 24 & 58 & \\
$1 \%$ & 24 & 62.16 & \\
$2 \%$ & 24 & 55.68 & \\
\hline
\end{tabular}

\section{Discussion}

We investigated the effect of different concentrations of MOSE of Trachyspermum ammi on weight gain of mice in this study and different concentrations of MOSE of Trachyspermum ammi $(0.5,1$, and $2 \%)$ was compared with control group after 15 days.

The results of this study showed that the weight gain in the control group was significantly different from the three groups fed with different concentrations of MOSE of Trachyspermum ammi, while the weight gain among the case groups did not show any significant difference. In a study on the effect of Trachyspermum ammi extract on the weight gain of mice, some studies demonstrated that Trachyspermum ammi extract had an effective role in the weight gain of the mice; $0.5 \%$ extract and then, $2 \%$ extract were the most effective concentrations in increasing the weight of the mice(Duke, 1997; Soni \& Parle, 2017). The results of this study are not consistent with the results of the present study, since in the present study, the weight gain of mice in the control group was significantly higher than the three case groups. Another study by Ibrahim et al. investigated and compared the effects of a diet including Trachyspermum ammi extract on seven-day-old chicks undergoing nine-week diet (with two concentrations of $2 \%$ and $10 \%$ Trachyspermum ammi extract), and showed that $10 \%$ concentration of this extract has toxic effects, which significantly reduces weight gain, causes hepatic nephropathy, and anemia, and increases cholesterol, fat, and uric acid. However, less severe effects were observed in $\%$ Trachyspermum ammi extract(Ibrahim et al., 2004). Unfortunately, few studies have been conducted on the effect of MOSE of Trachyspermum ammi on weight in Iran and worldwide. Therefore, except for a few studies, most studies carried out in this regard are indirectly related to the subject matter. Overall, the results of this study showed that the use of MOSE of Trachyspermum ammi in mice in the case groups caused changes in them, and they showed slower growth after consuming the extract. However, the finding of this study showed that the use of extract of this plant in the case group of mice was not significant in terms of weight gain. Therefore, the extract of this plant can not play a role in improving digestive tract and appetite or weight gain in mice.

\section{Acknowledgements}

We hereby express our deepest sense of gratitude to Vice Chancellor of Research and Technology Center of Babol University of Medical Sciences, for cooperation. 


\section{Conflicts of Interests}

All of authors declare no conflict of interests.

\section{References}

Bairwa, R., Sodha, R. S., \& Rajawat, B. S. (2012). Trachyspermum ammi. Pharmacognosy reviews, 6(11), 56-60. doi:10.4103/0973-7847.95871

Chahal, K., Dhaiwal, K., Kumar, A., Kataria, D., \& Singla, N. (2017). Chemical composition of Trachyspermum ammi L. and its biological properties: A review. J. Pharmacogn. Phytochem, 6(3), 131-140.

Duke, J. (1997). The ultimate compendium of Natural remedies from the worlds foremost Authority on healing and herbs. The Green Pharmacy Rodale press, 248, 334-463.

Hejazian, S. H., Bagheri, S. M., \& Safari, F. (2014). Spasmolytic and Anti-Spasmodic Action of Trachyspermum ammi Essence on Rat's Ileum Contraction. N Am J Med Sci, 6(12), 643-647. doi:10.4103/1947-2714.147982

Ibrahim, I., ElBadwi, S., Abdel, W. G., Bakhiet, A. O., Yagoub, S. O., \& Adam, S. (2004). Susceptibility of Bovans chicks to low dietary levels of Ammi visnaga and Artemisia herba-alba. Veterinary and human toxicology, 46(2), 67-69.

Ishikawa, T., Sega, Y., \& Kitajima, J. (2001). Water-soluble constituents of ajowan. Chemical and pharmaceutical bulletin, 49(7), 840-844.

Jeet, K., Devi, N., Narender, T., Sunil, T., Lalit, S., \& Thakur, R. (2012). Trachyspermum ammi: A comprehensive review (Vol. 3).

Markesbery, W. R. (1997). Oxidative stress hypothesis in Alzheimer's disease. Free Radical Biology and Medicine, 23(1), 134-147.

Mathew, N., Misra-Bhattacharya, S., Perumal, V., \& Muthuswamy, K. (2008). Antifilarial lead molecules isolated from Trachyspermum ammi. Molecules (Basel, Switzerland), 13(9), 2156-2168. doi:10.3390/molecules 13092156

Mohanty, B. (2017). A Review on Current Therapies and Challenges in Alzheimer's Disease and Role of Indian Spices in its Treatment as a Futuristic Approach. Neurol Clin Therapeut J, 1(101), 2.

Platel, K., \& Srinivasan, K. (2001). Studies on the influence of dietary spices on food transit time in experimental rats. Nutrition Research, 21(9), 1309-1314.

Saleem, U., Riaz, S., Ahmad, B., \& Saleem, M. (2017). Pharmacological screening of Trachyspermum ammi for antihyperlipidemic activity in Triton X-100 induced hyperlipidemia rat model. Pharmacognosy research, 9(Suppl 1), S34.

Sivropoulou, A., Papanikolaou, E., Nikolaou, C., Kokkini, S., Lanaras, T., \& Arsenakis, M. (1996). Antimicrobial and cytotoxic activities of Origanum essential oils. Journal of agricultural and Food Chemistry, 44(5), 1202-1205.

Soni, K., \& Parle, M. (2017). Anxiolytic Effects of Trachyspermum ammi Seeds in Mice. Journal of Pharmaceutical Sciences and Pharmacology, 3(1), 71-74.

Vasudevan, K., Vembar, S., Veeraraghavan, K., \& Haranath, P. (2000). Influence of intragastric perfusion of aqueous spice extracts on acid secretion in anesthetized albino rats. Indian journal of gastroenterology: official journal of the Indian Society of Gastroenterology, 19(2), 53-56.

\section{Copyrights}

Copyright for this article is retained by the author(s), with first publication rights granted to the journal.

This is an open-access article distributed under the terms and conditions of the Creative Commons Attribution license (http://creativecommons.org/licenses/by/4.0/). 